\title{
Impact of stress on oocyte quality and reproductive outcome
}

\author{
Shilpa Prasad ${ }^{1}$, Meenakshi Tiwari', Ashutosh N. Pandey', Tulsidas G. Shrivastav² and Shail K. Chaube ${ }^{1 *}$
}

\begin{abstract}
Stress is an important factor that affects physical and mental status of a healthy person disturbing homeostasis of the body. Changes in the lifestyle are one of the major causes that lead to psychological stress. Psychological stress could impact the biology of female reproduction by targeting at the level of ovary, follicle and oocyte. The increased level of stress hormone such as cortisol reduces estradiol production possibly by affecting the granulosa cell functions within the follicle, which results deterioration in oocyte quality. Adaptation of lifestyle behaviours may generate reactive oxygen species (ROS) in the ovary, which further affects female reproduction. Balance between level of ROS and antioxidants within the ovary are important for maintenance of female reproductive health. Physiological level of ROS modulates oocyte functions, while its accumulation leads to oxidative stress (OS). OS triggers apoptosis in majority of germ cells within the ovary and even in ovulated oocytes. Although both mitochondria- as well as death-receptor pathways are involved in oocyte apoptosis, OS-induced mitochondria-mediated pathway plays a major role in the elimination of majority of germ cells from ovary. OS in the follicular fluid deteriorates oocyte quality and reduces reproductive outcome. On the other hand, antioxidants reduce ROS levels and protect against OS-mediated germ cell apoptosis and thereby depletion of germ cells from the ovary. Indeed, OS is one of the major factors that has a direct negative impact on oocyte quality and limits female reproductive outcome in several mammalian species including human.
\end{abstract}

Keywords: Stress, ROS, Oxidative stress, Oocyte quality, Female reproductive outcome

\section{Background}

Stress is present at every level of society in the form of physical, social and psychological [1]. Lifestyle factors such as psychological stress, cigarette smoking, alcohol consumption, environmental and occupational exposures affect reproductive health of a female [1-3]. The psychological stress may be acute, episodic or chronic depending upon its length and depth of exposure. Acute stress is one of the most common types of psychological stress that occurs mainly due to demands and pressure. Frequent acute stress leads to episodic stress, while endless negative life events results in chronic stress. Reports suggest that chronic psychological stress results in poor in vitro fertilization (IVF) outcome possibly due to its negative impact at the level of ovary and oocytes [4-6].

\footnotetext{
*Correspondence: shailchaubey@gmail.com

'Cell Physiology Laboratory, Biochemistry Unit, Department of Zoology, Institute of Science, Banaras Hindu University, Varanasi 221005, UP, India Full list of author information is available at the end of the article
}

\section{Review}

Psychological stress and generation of ROS

Psychological stress due to negative life events lead to direct as well as indirect effects on female reproductive system [5]. Negative life events can directly induce the release of cortisol (a stress hormone), which inhibits estradiol biosynthesis from follicular cells leading to reduced quality and number of retrieved oocytes $[5,7,8]$. It can indirectly impact the reproductive health by changing lifestyle behaviours such as alcohol consumption, cigarette smoking habits etc., that results in the generation of reactive oxygen species (ROS) [5, 9-14]. Alcohol consumption and cigarette smoking have been reported to reduce fertility possibly due to increased level of ROS that causes oxidative stress (OS) [15-18]. Metabolism of alcohol involves formation of nicotinamide adenine dinucleotide $(\mathrm{NADH})$. The NADH induces conversion of xanthine dehydrogenase into its oxidase form that generates superoxide anions and thereby ROS [19, 20]. Smoking causes reduction of molecular oxygen and formation of 
superoxide radicals. The superoxide radical gets converted either into hydroxyl radical or hydrogen peroxide or both leading to generation of ROS [20]. The increased level of ROS deteriorates oocyte quality by inducing apoptosis [21-25]. There are several other factors that could lead to changes in lifestyle behaviours and generate ROS in a female [9]. Generation of ROS and their clearance through enzymatic and non-enzymatic antioxidants are important in the maintenance of oocyte quality and thereby reproductive health of a female [9, 23, 25-28].

The physiological level of ROS is beneficial during folliculogenesis, oocyte maturation and embryogenesis [10]. Studies from our laboratory suggest that less than $60 \mathrm{ng} /$ oocyte is a physiological level of ROS and maintains diplotene arrest in follicular oocytes [22, 29]. Generation of a moderate level of ROS (i.e., 60-80 ng/oocyte) may trigger meiotic resumption from diplotene arrest [22, 29]. The beneficial role of physiological level of ROS is further supported by the observations that the supplementation of antioxidants could inhibit maturation process in rat oocytes cultured in vitro [30]. However, stress can induce production of ROS beyond the physiological range (>80 ng/oocyte) that may result in cell cycle arrest and apoptosis in follicular oocytes [22, 29, 31]. Our studies suggest that increased level of ROS and decreased catalase activity might be involved during final stages of folliculogenesis and oocyte maturation in rat [30, 32]. However, accumulation of ROS beyond physiological level could lead to OS that may deteriorate oocyte quality and thereby affect reproductive outcome [10, 32-37]. The increased cellular metabolism and/or inhibition of enzymatic antioxidants in the ovary may result OS that induces cell cycle arrest and apoptosis both in vivo as well as in vitro [22, 27, 32, 35, 38, 39]. Thus, OS deteriorates oocyte quality, reduces fertilization and pregnancy rates and thereby reproductive outcome in several mammalian species including human $[23,31,32,38,40-42]$.

\section{Beneficial role of physiological level of ROS in ovary}

The female reproductive function is directly determined by the ovarian life span. Ovary is a metabolically active organ and serves as a germ cell reservoir during reproductive life span of female [43]. It consists approximately 0.3 million primordial follicles that contain diplotenearrested oocytes [43]. Pituitary gonadotropins surge induces steroidogenesis, follicular growth, development, maturation and ovulation in most of the mammalian

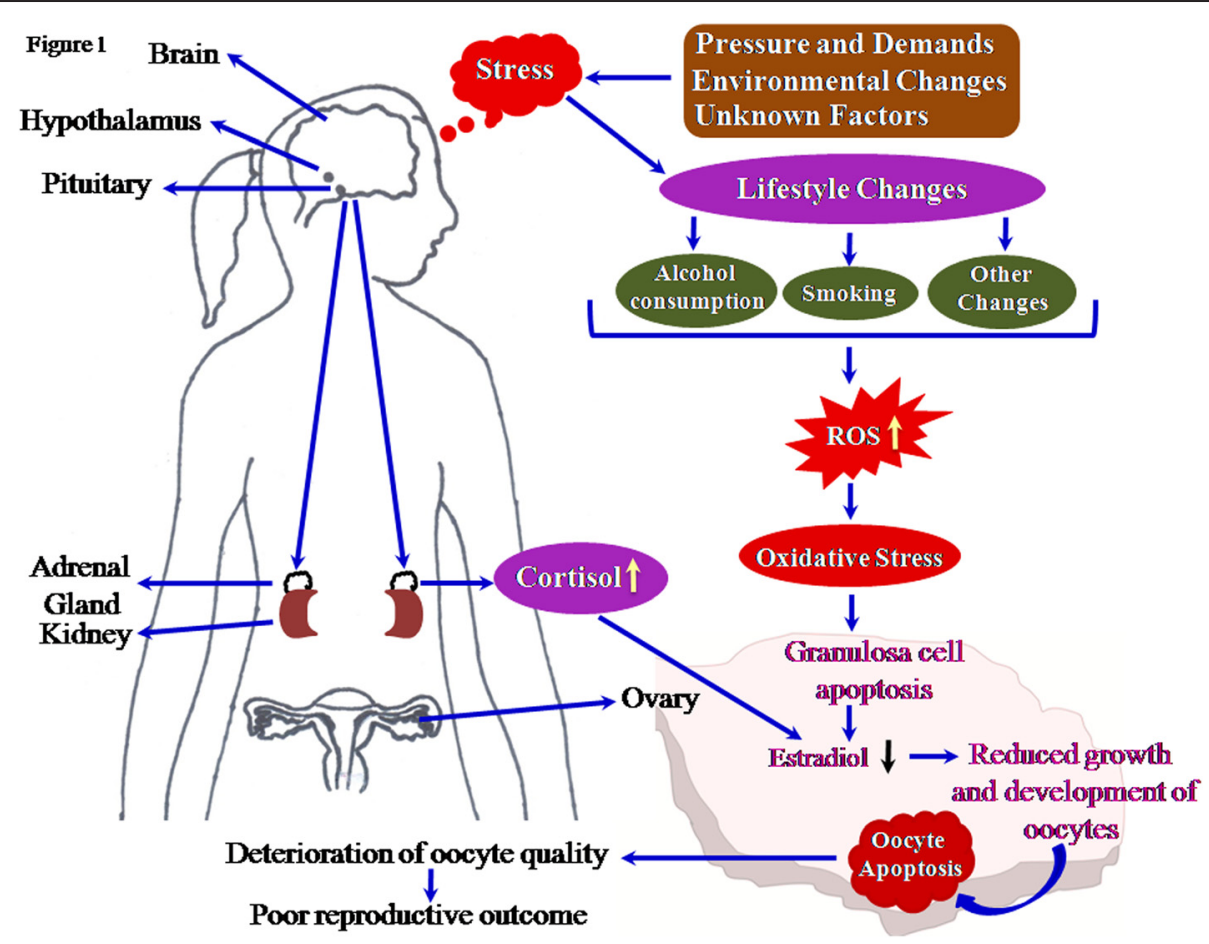

Fig. 1 Schematic diagram showing the impact of stress on reproductive outcome. Environmental changes, pressure and demands and several other factors generate psychological stress. The psychological stress induces lifestyle changes and cortisol production from adrenal gland which directly and indirectly affect the ovarian physiology. The lifestyle changes including alcohol consumption and smoking leads to increase level of ROS. The increased level of ROS results an oxidative stress. The increased cortisol as well as oxidative stress levels affects granulosa cell functions possibly by inducing apoptosis. The granulosa cell apoptosis results in reduced estradiol $17 ß$ biosynthesis in the ovary, which reduces growth and development of follicular oocytes and induces oocyte apoptosis. Apoptosis deteriorates oocyte quality leading to poor reproductive outcome in mammals including human 
species $[21,32,43]$. ROS is generated in the ovary due to increased metabolism during the final stages of folliculogenesis and follicular rupture, which results in the accumulation of ROS level possible due to decreased enzymatic antioxidants activity. This possibility is further supported by the observations that the decrease of catalase activity and increase of hydrogen peroxide as well as total ROS level trigger meiotic resumption from diplotene arrest in rat follicular oocytes [22, 27, 29, 31, 44]. A moderate increase of ROS level favors diplotene-arrested oocytes to resume meiosis inside the follicular microenvironment suggesting the beneficial role of ROS level within the ovary $[27,31,38,45,46]$. The high physiological level of ROS has been reported in antral follicles during final stages of folliculogenesis, which could be associated with final maturation of oocytes [21, 30, 47-50].

\section{Accumulation of ROS leads to OS and deteriorates oocyte quality}

Environmental changes, lifestyle changes, pathological conditions or drugs treatment may induce accumulation of ROS leading to OS that may have a negative impact on oocyte physiology by inducing apoptosis $[1,22,27,51]$. This notion is further strengthened by the observations that the OS caused granulosa cell apoptosis resulting in decreased estradiol 17ß level, ovulation rate and oocyte quality [45]. Studies from our laboratory suggest that OS-mediated granulosa cell apoptosis reduces granulosa cells-oocyte communication that affects supply of nutrients and maturation enabling factors affecting quality of preovulatory oocytes [40]. Further, OS induces shortening of telomere, chromosomal segregation disorders, oocyte fragmentation and fertilization failures thereby age-related decline in fertility [43, 52]. ROS-induced meiotic cell cycle arrest and apoptosis has recently been documented wherein we have proposed that a high ROS level (beyond physiological range) may trigger MPF destabilization and reduction in survival factors leading to mitochondria-mediated oocyte apoptosis [31]. This possibility is further strengthen by our in vitro studies that a transient increase in intracellular ROS leads to meiotic resumption from diplotene arrest, while further increase generates OS that induces cell cycle arrest and apoptosis [22, 29, 53, 54]. Similarly, high level of ROS has been reported to induce cell cycle arrest in human oocytes as well as in mouse embryos [29, 55-57]. Although OS induces cell cycle arrest and apoptosis in immature as well as mature oocytes, immature oocytes are more susceptible and quickly undergo OS-mediated morphological apoptotic changes including shrinkage, membrane blebbing, cytoplasmic granulation and degeneration $[22,41,58-60]$. The repeated ovarian stimulation by exogenous gonadotropin induces OS in the ovary and ovulation of poor quality of oocytes [61]. Both death-receptor as well as mitochondria-mediated pathways are involved in inducing oocyte apoptosis, OS-induced mitochondriacaspase mediated pathway plays a major role in elimination of germ cells from the cohort of ovary and deteriorates oocyte quality even after ovulation [32].

\section{Prevention and possible treatment against OS}

Changes in the lifestyle behaviour due to psychological stress resulting in habit of alcohol consumption, cigarette smoking, etc. induce generation of $\operatorname{ROS}[5,9,10]$. Therefore, adaptation of healthy lifestyle as well as avoiding the consumption of alcohol, habit of smoking and use

Table 1 List of studies showing effect of stress on ROS production and oocyte quality

\begin{tabular}{|c|c|c|c|}
\hline S. No. & Effects of stress on Ros production and oocyte quality & $\begin{array}{l}\text { Experimental } \\
\text { model }\end{array}$ & References \\
\hline 1. & $\begin{array}{l}\text { Stressful life events cause release stress hormone and } \\
\text { impair follicular maturation in ovary }\end{array}$ & Human & Lancastle and Boivin, 2005 [7], Ebbesen et al., 2009 [5] \\
\hline 2. & $\begin{array}{l}\text { Stressful life events leads to maladapted lifestyle behaviours } \\
\text { i.e. alcohol and cigarette consumption }\end{array}$ & Human & $\begin{array}{l}\text { Veenstra et al, } 2007 \text { [11], Bacharach et al., 2008, } \\
\text { Hooper et al., } 2008 \text { [13], Ogden et al., 2009[14] }\end{array}$ \\
\hline 3. & Stress induces poor IVF outcome & Human & Barzilai Pesach et al., 2006 [2], Ebbesen et al., 2009 [5] \\
\hline 4. & Stress generates ROS and reduces oocyte quality & Mice & Kala and Nivsarkar, 2016 \\
\hline 5. & alcohol and cigarette consumption reduces fertility in women & Human & Howe et al., 1985 [16], Hakim et al., 1998 [17] \\
\hline 6. & Alcohol consumption increases ROS level & $\begin{array}{l}\text { Rat } \\
\text { Human }\end{array}$ & $\begin{array}{l}\text { Kato et al., } 1990 \text { [19], } \\
\text { Videla et al., } 2009 \text { [18] }\end{array}$ \\
\hline 7. & OS triggers oocyte apoptosis & $\begin{array}{l}\text { Rat } \\
\text { Human }\end{array}$ & $\begin{array}{l}\text { Chaube et al., } 2005 \text { [22], } 2006 \text { [38], } 2008 \text { [53], } \\
\text { Tripathi et al., 2011, Tripathi and Chaube, 2012, } \\
\text { Tamura et al., } 2008\end{array}$ \\
\hline 8. & $\begin{array}{l}\text { Increase ROS level reduces oocyte quality and reproductive } \\
\text { outcome }\end{array}$ & Rat & $\begin{array}{l}\text { Chaube et al., 2006, 2008, Tripathi et al., } 2011 \text { [27], } \\
\text { Tripathi and Chaube, [39]2012, }\end{array}$ \\
\hline & & Human & Tamura et al., 2008 [23] \\
\hline
\end{tabular}


of recreational drugs could reduce level of OS and their negative impact on female reproductive outcome $[1,3,62]$. To minimize OS, antioxidants are useful since they scavenge free radicals and reduce ROS level in the body [63]. Both enzymatic as well as non-enzymatic antioxidants are used to reduce level of ROS and thereby OS [63]. Enzymatic antioxidants such as superoxide dismutase (SOD), catalase, glutathione peroxidase (GPx) and glutathione oxidase and non-enzymatic antioxidants such as vitamin $\mathrm{C}$, taurine, hypotaurine, vitamin $\mathrm{E}, \mathrm{Zn}$, selenium (Se), betacarotene, and carotene could be beneficial to overcome this problem $[63,64]$. Animal studies suggest that antioxidant supplementation is beneficial to overcome deleterious effects of stress induced OS on mouse oocytes [65]. Melatonin has been considered as one of the potent naturally occurring antioxidants because it prevents OS-mediated deterioration of oocyte quality in rat $[23,27]$ and improve reproductive outcome in human [66, 67]. Supplementation of daily food practices with different antioxidant providing mediums such as fresh green leafy vegetables, antioxidant rich legumes and plant products may provide support to compensate OS [20].

\section{Conclusions}

Environmental changes, pressure and demands and several other factors may generate psychological stress. Psychological stress increases production of cortisol that stimulates lifestyle changes. These changes may directly or indirectly affect the physiology of the ovary. Cortisol induces granulosa cell apoptosis and affects estradiol $17 ß$ biosynthesis in the ovary. Reduced level of estradiol in the ovary impairs growth and development of follicles and deteriorates oocyte quality by inducing apoptosis (Fig. 1). High level of ROS in the ovary generates OS, which induces granulosa cell as well as oocyte apoptosis. Indeed, stress could be one of the major causative factors that generates OS, induces apoptosis, deteriorates oocyte quality and reduces reproductive outcome in mammals including human (Table 1). Hence, adaptation of healthy lifestyle, avoiding consumption of alcohol, smoking habit and use of antioxidants as food supplement could be beneficial to overcome stress induced OS-mediated deterioration in oocyte quality and poor reproductive outcome.

\footnotetext{
Abbreviations

GPx: glutathione peroxidase; IVF: In vitro fertilization; NADH: nicotinamide adenine dinucleotide; OS: oxidative Stress; ROS: reactive oxygen species; SOD: superoxide dismutase.
}

\section{Competing interests}

The authors declare that they have no competing interests.

\section{Authors' contributions}

$\mathrm{SP}, \mathrm{MT}$, and ANP searched the literature and wrote the initial draft of manuscript. SKC and TGS suggested the structure, revised and finished the final version of manuscript. All authors read and approved the final manuscript.

\section{Acknowledgement}

This study was financially supported by Department of Biotechnology, Ministry of Science and Technology, Government of India (Grant no. BT/PR4225/AAQ/1/492/2011)

\section{Author details}

'Cell Physiology Laboratory, Biochemistry Unit, Department of Zoology, Institute of Science, Banaras Hindu University, Varanasi 221005, UP, India. ${ }^{2}$ Department of Reproductive Biomedicine, National Institute of Health and Family Welfare, Baba Gang Nath Marg, Munirka, New Delhi 110067, India.

Received: 21 January 2016 Accepted: 22 March 2016

Published online: 29 March 2016

\section{References}

1. Sharma R, Biedenharn KR, Fedor JM, Agarwal A. Lifestyle factors and reproductive health: taking control of your fertility. Reprod Biol Endocrinol. 2013;11:66.

2. Barzilai Pesach V, Sheiner EK, Sheiner E, Potashnik G, ShohamVardi I. The effect of women's occupational psychologic stress on outcome of fertility treatments. J Occup Environ Med. 2006;48:56-62.

3. Lykeridou K, Gourounti K, Sarantaki A, Loutradis D, Vaslamatzis G, et al. Occupational social class, coping responses and infertility related stress of women undergoing infertility treatment. J Clin Nurs. 2011;20:1971-80.

4. Demyttenaere K, Nijs P, Evers-Kiebooms G, Koninckx PR. Coping and the ineffectiveness of coping influence the outcome of in vitro fertilization through stress responses. Psycho Neuroendocrinol. 1992;17:655-65.

5. Ebbesen SMS, Zachariae R, Mehlsen MY, Thomsen D, Hojgaard A, Ottosen L, et al. Stressful life events are associated with a poor in-vitro fertilization (IVF) outcome: a prospective study. Hum Reprod. 2009;24:2173-82.

6. Lakatos E, Szabo G, Szigeti F, Balog P. Relationships between psychological well-being, lifestyle factors and fertility. Orv Hetil. 2015;156:483-92.

7. Lancastle D, Boivin J. Dispositional optimism, trait anxiety, and coping: unique or shared effects on biological response to fertility treatment? Health Psychol. 2005:24:171-8.

8. Kala M, Nivsarkar M. Role of cortisol and superoxide dismutase in psychological stress induced anovulation. Gen Comp Endocrinol. 2016;225:117-24.

9. Ruder EH, Hartman TJ, Blumberg J, Goldman MB. Oxidative stress and antioxidants: exposure and impact on female fertility. Hum Reprod Update. 2008; 14:345-57.

10. Lázár L. The Role of Oxidative Stress in Female Reproduction and Pregnancy, Oxidative Stress and Diseases, Dr. Volodymyr Lushchak (Ed.), 2012; ISBN: 978-953-51-0552-7, InTech, Available from: http://www. intechopen.com/books/oxidative-stress-and-diseases/the-role-of-oxidativestress-in-femalereproduction-and-pregnancy.

11. Veenstra MY, Lemmens PH, Friesema IH, Tan FE, Garretsen HF, Knottnerus $J A$, et al. Coping style mediates impact of stress on alcohol use: a prospective population-based study. Addiction. 2007:102:1890-8.

12. Bacharach SB, Bamberger PA, Doveh E. Firefighters, critical incidents, and drinking to cope: the adequacy of unit-level performance resources as a source of vulnerability and protection. J Appl Psychol. 2008;93:155-69.

13. Hooper R, Rona RJ, Jones M, Fear NT, Hull L, Wessely S. Cigarette and alcohol use in the UK Armed Forces, and their association with combat exposures: a prospective study. Addict Behav. 2008;33:1067-71.

14. Ogden J, Stavrinaki M, Stubbs J. Understanding the role of life events in weight loss and weight gain. Psychol Health Med. 2009;14:239-49.

15. Pryor WA, Prier DG, Church DF. Electron-spin resonance study of mainstream and sidestream cigarette smoke: nature of the free radicals in gas-phase smoke and in cigarette tar. Environ Health Perspect. 1983:47:345-55.

16. Howe G, Westhoff C, Vessey M, Yeates D. Effects of age, cigarette smoking, and other factors on fertility: findings in a large prospective study. Br Med 」 (Clin Res Ed). 1985;290:1697-700.

17. Hakim RB, Gray RH, Zacur H. Alcohol and caffeine consumption and decreased fertility. Fertil Steril. 1998;70:632-7.

18. Videla LA. Oxidative stress signaling underlying liver diseases and hepatoprotective mechanism. World J Hepatol. 2009;31:72-8.

19. Kato S, Kawase T, Alderman J, Inatomi N, Lieber CS. Role of xanthine oxidase in ethanol-induced lipid peroxidationin rats. Gastroenterology. 1990;98:203-10.

20. Aseervatham GS, Sivasudha T, Jeyadevi R, Arul AD. Environmental factors and unhealthy lifestyle influence oxidative stress in humans-an overview. Environ Sci Pollut Res Int. 2013;20:4356-69. 
21. Agarwal A, Gupta S, Sharma RK. Role of oxidative stress in female reproduction. Reprod Biol Endocrinol. 2005;3:28.

22. Chaube SK, Prasad PV, Thakur SC, Shrivastava TG. Hydrogen peroxide modulates meiotic cell cycle and induces morphological features characteristics of apoptosis in rat oocytes cultured in vitro. Apoptosis. 2005;10:863-75.

23. Tamura H, Takasaki A, Miwa I, Taniguchi K, Maekawa R, Asada H, et al. Oxidative stress impairs oocyte quality and melatonin protects oocytes from free radical damage and improves fertilization rate. J Pineal Res. 2008;44:280-7.

24. Revelli A, Piane LD, Casano S, Molinari E, Massobrio M, Rinaudo P. Follicular fluid content and oocyte quality: from single biochemical markers to metabolomics. Reprod Biol Endocrinol. 2009;7:40

25. Combelles $\mathrm{CMH}$, Gupta S, Agarwal A. Could oxidative stress influence the in-vitro maturation of oocytes? Reprod Biomed Online. 2009;18:864-80.

26. Sugino N. Reactive oxygen species in ovarian physiology. Reprod Med Bio. 2005;4:31-44.

27. Tripathi A, Premkumar KV, Pandey AN, Khatun S, Mishra SK, Shrivastav TG, et al. Melatonin protect against clomiphene citrate-induced generation of free radicals and egg apoptosis in rat. Eur J Pharmacol. 2011;667:419-24.

28. Khan SN, Shaeib F, Najafi T, Kavdia M, Gonik B, Saed GM, et al. Diffused intra-oocyte hydrogen peroxide activates myeloperoxidase and deteriorates oocyte quality. PLoS One. 2015;10:e0132388.

29. Tripathi A, Khatun S, Pandey AN, Mishra SK, Chaube R, Shrivastava TG, et al. Intracellular levels of hydrogen peroxide and nitric oxide in oocyte at various stages of meiotic cell cycle and apoptosis. Free Radic Res. 2009;43:287-94.

30. Pandey AN, Tripathi A, Premkumar KV, Shrivastav TG, Chaube SK. Reactive oxygen and nitrogen species during meiotic resumption from diplotene arrest in mammalian oocytes. J Cell Biochem. 2010;111:521-8.

31. Tiwari M, Prasad S, Tripathi A, Pandey AN, Singh AK, Shrivastav TG, Chaube SK Involvement of reactive oxygen species in meiotic cell cycle regulation and apoptosis in mammalian oocytes. Reactive Oxygen Species. 2016;1:110-6.

32. Tiwari M, Prasad S, Tripathi A, Pandey AN, Ali I, Singh AK, et al. Apoptosis in mammalian oocytes: A review. Apoptosis. 2015;20:1019-25.

33. Agarwal A, Allamaneni SS. Role of free radicals in female reproductive diseases and assisted reproduction. Reprod Biomed Online. 2004;9:338-47.

34. Agarwal A, Gupta S, Sharma R. Oxidative stress and its implications in female infertility-a clinician's perspective. Reprod Biomed Online. 2005;11: 641-50.

35. Goud AP, Goud PT, Diamond MP, Gonik B, Abu-Soud HM. Reactive oxygen species and oocyte aging: Role of superoxide, hydrogen peroxide, and hypochlorous acid. Free Radic Biol Med. 2008:44:1295-304.

36. Winterbourn CC, Hampton MB. Thiol chemistry and specificity in redox signaling. Free Radic Biol Med. 2008;45:549-61.

37. Pandey AN, Chaube SK. Reduction of nitric oxide level leads to spontaneous resumption of meiosis in diplotene-arrested rat oocytes cultured in vitro. Exp Biol Med (Maywood). 2015;240:15-25.

38. Chaube SK, Prasad PV, Tripathi V, Shrivastav TG. Clomiphene citrate inhibit gonadotropin-induced ovulation by reducing cyclic adenosine 3',5'-cyclic monophosphate and prostaglandin E2 levels in rat ovary. Fertl Sterl. 2006; 86:1106-11.

39. Tripathi A, Chaube SK. High level of cytosolic free calcium signals apoptosis through the mitochondria-caspase mediated pathway in rat eggs cultured in vitro. Apoptosis. 2012;17:439-48.

40. Chaube SK, Shrivastav TG, Prasad S, Tiwari M, Tripathi A, Pandey AN, et al. Clomiphene citrate induces ROS-mediated apoptosis in mammalian oocytes. Open J Apoptosis. 2014;3:52-8.

41. Chaube SK, Shrivastav TG, Tiwari M, Prasad S, Tripathi A, Pandey AK. Neem (Azadirachta indica L.) leaf extract deteriorates oocyte quality by inducing ROS-mediated apoptosis in mammals. SpringerPlus. 2014;3(1-7):464.

42. Luderer U. Ovarian toxicity from reactive oxygen species. Vitam Horm. 2014; 94:99-127.

43. Tatone C, Emidio GD, Vitti M, Carlo MD, Santini Jr. S, D'Alessandro AM et al. Sirtuin Functions in Female Fertility: Possible Role in Oxidative Stress and Aging. Oxid Med Cell Longev. 2015; http://dx.doi.org/10.1155/2015/659687

44. Behrman HR, Kodaman PH, Preston SL, Gao S. Oxidative stress and the ovary. J Soc Gynecol Investig. 2001;8:S40-2.

45. Tripathi A, Shrivastav TG, Chaube SK. An increase of granulosa cell apoptosis mediates aqueous neem (Azadirachta indica) leaf extract induced oocyte apoptosis in rat. Intl J Basic Med Res. 2013;3:27-36.

46. Tiwari M, Chaube SK. Moderate increase of reactive oxygen species triggers meiotic resumption in rat follicular oocytes. J Obstet Gynaecol Res. 2016. doi:10.1111/jog.12938.
47. Singh D, Pandey RS. Changes in catalase activity and hydrogen peroxide level in rat ovary during estrous cycle and induction of catalase in rat ovary by estradiol-17 beta. Indian J Exp Biol. 1998;36:421-3.

48. Fujii J, luchi Y, Okada F. Fundamental role of reactive oxygen species and protective mechanism in the female reproductive systems. Reprod Biol Endocrinol. 2005:3:43-52.

49. Basini G, Simona B, Santini SE, Grasselli F. Reactive oxygen species and antioxidant defences in swine follicular fluids. Reprod Fertil Dev. 2008;20:269-74.

50. Rizzo A, Minoia G, Trisolini C, Mutinati M, Spedicato M, Jirillo F, et al. Reactive oxygen species (ROS): Involvement in bovine follicular cysts etiopathogenesis. Immunopharmacol Immunotoxicol. 2009:31:631-5.

51. Tatemoto H, Sakurai N, Muto N. Protection of porcine oocytes against apoptotic cell death caused by oxidative stress during in vitro maturation: role of cumulus cells. Biol Reprod. 2000;63:805-10.

52. Ishii T, Miyazawa M, Takanashi Y, Tanigawa M, Yasuda K, Onouchi H, et al. Genetically induced oxidative stress in mice causes thrombocytosis, splenomegaly and placental angiodysplasia that leads to recurrent abortion. Redox Biol. 2014;2:679-85.

53. Chaube SK, Khatun S, Mishra SK, Shrivastav TG. Calcium ionophore-induced egg activation or apoptosis is associated with the generation of intracellular hydrogen peroxide. Free Rad Res. 2008:42:212-20.

54. Pandey AN, Chaube SK. A moderate increase of hydrogen peroxide level is beneficial for spontaneous resumption of meiosis from diplotene arrest in rat oocytes cultured in vitro. BioRes Open Access. 2014;3:183-91.

55. Liu L, Trimarchi JR, Keefe DL. Thiol oxidation induced embryonic cell death in mice prevented by antioxidant Dithiothretol. Biol Reprod. 1999;61:1162-9.

56. Liu L, Keefe DL. Cytoplasm mediated both developmental and oxidation induced apoptotic cell death in mouse zygote. Biol Reprod. 2000;62:1828-34.

57. Tamanini C, Basini G, Grasselli F, Tirelli M. Nitric oxide and ovary. J Anim Sci. 2003;81(E. Suppl. 2):E1-7.

58. Terranova PF, Tayler CC. Apoptosis (cell death). Encyclopedia Reproduct. 1999;1:261-73.

59. Tada-Okawa S, Oikawa S, Kawanishi M, Yamada M, Kawanishi S. Generation of hydrogen peroxide precedes loss of mitochondrial membrane potential during DNA alkylation-induced apoptosis. FEBS Lett. 1999:442:65-9.

60. Men H, Manson RL, Parrish JJ, Rutledge JJ. Degeneration of cryopreserved bovine oocytes via apoptosis during subsequent culture. Cryobiology. 2003; 47:73-81.

61. Chao HT, Lee SY, Lee HM, Liao TL, Wei YH, Kao SH. Repeated ovarian stimulations induce oxidative damage and mitochondrial DNA mutations in mouse ovaries. Ann N Y Acad Sci. 2005;1042:148-56.

62. Crha I, Hruba D, Ventruba P, Fiala J, Totusek J, Visnová H. Ascorbic acid and infertility treatment. Cent Eur J Public Health. 2003;11:63-7.

63. Agarwal A, Aponte-Mellado A, Premkumar BJ, Shaman A, Gupta S. The effects of oxidative stress on female reproduction: a review. Reprod Biol Endocrinol. 2012;10:49.

64. Sharma RK, Agarwal A. Role of reactive oxygen species in gynecologic diseases. Reprod Med Biol. 2004;3:177-99.

65. Lian HY, Gao Y, Jiao GZ, Sun MJ, Wu XF, Wang TY, et al. Antioxidant supplementation overcomes the deleterious effects of maternal restraint stress-induced oxidative stress on mouse oocytes. Reproduction. 2013; 146:559-68.

66. Eryilmaz OG, Devran A, Sarikaya E, Aksakal FN, Mollamahmutoglu L, Cicek N. Melatonin improves the oocyte and the embryo in IVF patients with sleep disturbances, but does not improve the sleeping problems. J Assist Reprod Genet. 2011;28:815-20

67. Batioglu AS, Sahin U, Gürlek B, Ozturk N, Unsal E. The efficacy of melatonin administration on oocyte quality. Gynecol Endocrinol. 2012;28:91-3. 